\title{
Unconventional dentures - A literature review
}

\author{
Shaik Riyaz Basha ${ }^{1, *}$, M. Sujesh ${ }^{2}$, Sadaf Alvi $^{3}$, Nirban Mitra ${ }^{4}$ \\ ${ }^{\mathbf{1}}$ Associate Professor, Dept. of Prosthodontics, Malla Reddy Institute of Dental Sciences, Hyderabad, Telangana, ${ }^{2}$ Professor, Dept. \\ of Prosthodontics, Mamta Dental College, Khammam, Telangana, ${ }^{3,4}$ Senior Lecturer, ${ }^{3}$ Dept. of Oral Pathology, ${ }^{4}$ Dept. of \\ Prosthodontics, ${ }^{3,4}$ Malla Reddy Institute of Dental Sciences, Hyderabad, Telangana, India
}

*Corresponding Author:

Email: riyazbasha007@gmail.com

\begin{abstract}
Routine complications faced by the dentist include atrophic ridge, microstomia, flabby tissue, xerostomia, bony exostosis, labially inclined premaxilla, esthetic demand, bruxism, systemic disorders, patient's demand for duplicating dentures, etc. Management of these difficulties can be done by proper incorporating of suitable materials and advanced techniques. This article describes the unconventional approaches to various modalities so as to provide ultimate satisfaction for the patient.
\end{abstract}

Keywords: Unconventional dentures, Liquid supported dentures, Xerostomia.

\section{Introduction}

Complete loss of teeth leads to significant psychological trauma, loss of masticatory efficiency, loss of the supporting alveolar bone, reduced vertical dimension, lack of support for the facial musculature and altered jaw functions. Advancing age can lead to exaggerated tissue folds and tissue atrophy, loss of tissue support, increase in the number of creases and folds on the face and loss of tonicity of the muscles and skin. ${ }^{1}$ These changes lead to reduced vertical dimension with a collapsed lower third of the face and affects the overall esthetics of the patient. The external appearance of a complete denture patient is characterised by the presence of deep nasolabial folds, lack of lip support as indicated by the loss of vermilion border and dropping of the corner of the lips. Denture esthetics is defined as the effect produced by a dental prosthesis that affects the beauty and attractiveness of the patient. ${ }^{2}$ Denture esthetics begins at the first consultation visit of the patient when the esthetic expectations of the patient from the denture need to be assessed and estimated thoroughly. The goal of complete denture prosthodontics is to ensure that the facial musculature is restored of the support and tonicity that has set in due to the complete loss of teeth. This could be achieved either by increasing the thickness of the dentures or by providing the ideal vertical dimension so as to restore the physiologic muscle length and eliminate the pseudoprognathic appearance. ${ }^{3}$ The role of a Prosthodontist is to restore the lost function, provide better esthetics and improve the tonicity of the orofacial muscles. Restoring esthetics with dentures by replacing the loss of all these various structures and restoring function can be carried out either with.

1. Conventional dentures

2. Unconventional dentures

Unconventional dentures can be used to provide either lost support of the orofacial muscles or to improve muscle tonicity or for better orofacial functions etc.
Restoration of Esthetics: Unconventional dentures have been used for the restoration of esthetics of the buccal musculature by the use of cheek plumpers. Artificial denture cheek plumpers were proposed by Larsen ${ }^{4}$ et al in 1976 for the management of patients with specific esthetic concern. He described a technique for the restoration of the lost tonicity of the buccal musculature. The same technique of cheek plumpers was successfully used by Sunil Kumar et al. ${ }^{5}$ They described, in their case report, the management of a patient with severe loss of buccal musculature, tonicity of the skin and lack of support from the previous denture. Major concerns of the patient were poor esthetics, unsupported oral musculature and slumped cheeks which were not addressed by the previous dentures. Thus, better esthetic was achieved in the case reported by them by modifying the conventional dentures and including cheek plumpers for restoration of esthetics and function. Thus, denture esthetics has gone beyond the mere selection of teeth size, shape and shade. ${ }^{6}$ Cheek plumpers help to achieve better esthetics by providing support to the cheek musculature which has had contour changes as a result of loss of vertical dimension. Loss of elasticity of connective tissue results in the excessive loss of support for the buccal musculature.

Management of Patients with Xerostomia: Unconventional dentures have been effectively used in the management of patient suffering from xerostomia. These patients complain of a dry mouth, difficulty in normal oral functions including eating, speaking and swallowing. ${ }^{7}$ Extreme discomfort in wearing dentures is a common complaint. ${ }^{8}$ Xerostomia can occur due to many possible causes such as in syndromes and diseases associated with reduced salivary flow Sjogrens syndrome and diseases of the salivary gland; stress; post irradiation sequelae and poor general health of the patient. Management of these patients is routinely done with medication or with gustatory stimulation of the salivary glands by mastication of 
sugar free chewing gums or lozenges is helpful..$^{9-11}$ Soft denture liners are often used for the management of these patients. Unconventional dentures as a treatment modality have been used in the management of patients with xerostomia by the incorporation into dentures of reservoirs containing saliva substitutes. Case reports by Vergo et $\mathrm{al}^{12}$ in 1981 , Toljanic et $\mathrm{al},{ }^{13}$ Mendoza et $\mathrm{al}^{14}$ in 1993 and Sinclair et $\mathrm{al}^{15}$ in 1996 presented various techniques for the fabrication of these reservoir dentures which could be very effectively used in the management of patients with xerostomia.

Vergo et $\mathrm{al}^{12}$ reported on an unconventional denture which included a reservoir for dispensing artificial saliva for patients with oropharyngeal carcinomas. The authors used the reservoir denture to contribute to successful oral rehabilitation of patients with postirradiation xerostomia. Toljanic et $\mathrm{al}^{13}$ designed unconventional dentures that included a reservoir for saliva substitute in the palate of the maxillary denture for patients with xerostomia. All patients were reported to have found the reservoir system helpful in the control of xerostomia.

Mendoza et $\mathrm{al}^{14}$ in their paper presented a new form of the reservoir denture, which was used successfully in a patient for the management of xerostomia where other treatment modalities had failed. A new technique for the construction of a full, mandibular reservoir denture was presented. The denture was named the split denture as it was split into two sections with a clear acrylic base which contained the reservoirs and a pink acrylic upper section which contained the denture teeth. This modification provided constant salivary flow for the patient and had the added advantage of allowing easy cleaning of the reservoirs.

The split reservoir denture described by Mendoza et $\mathrm{al}^{14}$ provided a good technique for the management of patients with xerostomia. The authors also suggested that the split denture could find additional usage in the management of patients with post radiation xerostomia. The technique proposed by these authors had additional advantages of being easy to clean and adjustment of the reservoirs. Additionally, it also allowed the patient to clearly visualize the levels of saliva substitute within the chamber. The clinical stages during construction were routine and required little additional chair-side time. However, laboratory stages were time consuming and precision was essential to ensure accurate and smoothly fitting segments. Additionally, repairs and relines of a split denture are more complex. The authors also suggested that proper case selection was extremely important for using the split reservoir denture technique. Their recommendations included cases with good vertical dimension as sufficient clearance was required for the reservoirs and cases with minimal undercuts as accurate reseating of processed dentures would be extremely difficult in cases with large undercuts.
Sinclair et $\mathrm{al}^{15}$ reported that complete dentures are highly uncomfortable in patients with reduced salivary flow. A denture design which can combine salivary substitutes with an effective and hygienic saliva dispensing system is yet to be reached. They analyzed the difficulties with previous methods and devised a new unconventional reservoir denture that maximized capacity and was easy to maintain by the wearer.

Burhanpurwala et $\mathrm{al}^{16}$ presented a new reservoir denture technique for the management of a patient with xerostomia. They reported on a new form of reservoir denture which was fabricated by using a dual flasking method. The technique resulted in a reservoir denture that provided good lubrication to the oral tissues which was also hygienic and was made from routine denture base material in contrast to that reported by Mendoza et al. The two piece lower reservoir denture presented by these authors was simpler, easier to fabricate and offers an alternate method for the management of patients with xerostomia.

Management of Cases with Extreme Resorption: Prosthetic rehabilitation in cases with extreme alveolar resorption is considered difficult as these ridges are narrow, more constriction of the residual ridges as resorption progress, less supporting tissues. Addition of weight to the mandibular denture has been suggested as a way of increasing the retention by some authors ${ }^{17}$. Reduction of weight of the maxillary denture was proposed for increasing the retention in patients with extremely resorbed ridges. This technique has been extremely beneficial when constructing an obturator for the restoration of a large maxillofacial defect. ${ }^{18,19}$

Weight reduction of dentures is one of the accepted techniques for the management of patients who require obturators or to make the denture lighter in patients with extreme alveolar resorption. This weight reduction is achieved using a solid 3-dimensional spacer, including dental stone, ${ }^{20-26}$ cellophane wrapped asbestos, ${ }^{27}$ silicone putty, ${ }^{28,29}$ or modelling clay $^{30,31}$ which are incorporated during the processing of the final denture. Multiple and separate pieces of the prosthesis are polymerized around a 3-dimensional spacer. Following the initial polymerization process, the solid spacer is removed. Individual pieces of the prosthesis are then joined using autopolymerizing acrylic resin repair techniques.

\section{Conclusion}

Denture esthetics has thus gone beyond the just replacement of teeth with proper selection of size, shade and shape. Better rehabilitation of the edentulous patient is possible with appropriate use of these unconventional dentures. These dentures have been found to be extremely useful in several patients suffering from xerostomia and in those patients with extreme loss of orofacial esthetics. Unconventional dentures, can thus be considered as an advantageous option in the management of such patients. 


\section{References}

1. Tautin FS. Denture esthetics is more than teeth selection. J Prosthet Dent 1978:40:127-30.

2. Glossary of prosthodontic terms 2005:94:10-92

3. Lomdardi RE. The principles of visual perception and their clinical application to denture esthetics. J Prosthet Dent 1973:29:358.

4. Larsen SJ, Carter JF, Abrahamian HA. Prosthetic support for unilateral facial paralysis. J Prosthet Dent 1976:35:192-201.

5. Sunil Kumar MV, Harikesh Rao, Kanwardeep Singh Sohi. Artificial cheek plumper's: A step ahead in denture esthetics - a case report. Indian J Stomatol 2011:2(2):134-137.

6. Clair F, Picard Jr. Complete denture esthetics. J Prosthet Dent 1958:8:252-259.

7. Moore PA, Guggenheimer J, Etzel KR, Weyant RJ, Orchard T. Type 1 diabetes mellitus, xerostomia, and salivary flow rates. Oral Surg Oral Med Oral Pathol Oral Radiol Endod 2001;92:281-291.

8. Locker D. Subjective reports of oral dryness in an older adult population. Community Dent Oral Epidemiol 1993;21:165-168

9. Itthagarun A, Wei SH. Chewing gum and saliva in oral health. J Clin Dent 1997;8:159-162.

10. Risheim H, Arneberg P. Salivary stimulation by chewing gum and lozenges in rheumatic patients with xerostomia. Scand J Dent Res 1993;101:40-43.

11. Daniels TE, Wu AJ. Xerostomia - clinical evaluation and treatment in general practice. J Calif Dent Assoc 2000;28:933-941.

12. Vergo TJ, Kadish SP. Dentures as artificial saliva reservoirs in the irradiated edentulous cancer patient with xerostomia: a pilot study. Oral Surg Oral Med Oral Pathol 1981;51:229-233.

13. Toljanic JA, Zucuskie TG, Use of a palatal reservoir in denture patients with xerostomia. J Prosthet Dent Volume 1984:52(4):540-544.

14. AR Mendoza, MJ Tomlinson. The split denture: A new technique for artificial saliva reservoirs in mandibular dentures. Australian Dental Journal 2003;48:(3):190-194.

15. Sinclair GF, Frost PM, Walter JD. New design for an artificial saliva reservoir for the mandibular complete denture. J Prosthet Dent 1996;75:276-280.
16. Burhanpurwala MA, Magar SK, Bhandari AJ, Gangadhar SA. Management of an edentulous patient. JIPS 2009:9(2):92-95.

17. Wormley JH, Brunton DA. Weighted mandibular dentures. J Prosthet Dent 1974;32:101-2.

18. El Mahdy AS. Processing a hollow obturator. J Prosthet Dent 1969;22: 682-6.

19. Brown KE. Fabrication of a hollow-bulb obturator. $J$ Prosthet Dent 1969;21:97-103.

20. Nidiffer TJ, Shipman TH. Hollow bulb obturator for acquired palatal openings. J Prosthet Dent 1957;7:12634.

21. Rahn AO, Boucher LJ. Maxillofacial prosthetics: principles and concepts. St. Louis: Elsevier; 1970. p. 95

22. Buckner H. Construction of a denture with hollow obturator, lid, and soft acrylic lining. J Prosthet Dent 1974;31:95-9.

23. Browning JD, Kinderknecht J. Fabrication of a hollow obturator with fluid resin. J Prosthet Dent 1984;52:891-5.

24. Fattore LD, Fine L, Edmonds DC. The hollow denture: an alternative treatment for atrophic maxillae. J Prosthet Dent 1988;59:514-6.

25. Gardner LK, Parr GR, Rahn AO. Simplified technique for the fabrication of a hollow obturator prosthesis using vinyl polysiloxane. J Prosthet Dent 1991;66:60-2.

26. McAndrew KS, Rothenberger S, Minsley GE. An innovative investment method for the fabrication of a closed hollow obturator prosthesis. J Prosthet Dent 1998;80:129-32.

27. Worley JL, Kniejski ME. A method for controlling the thickness of hollow obturator prostheses. J Prosthet Dent 1983;50:227-9.

28. Holt RA Jr. A hollow complete lower denture. J Prosthet Dent 1981;45:452-4.

29. Jhanji A, Stevens ST. Fabrication of one-piece hollow obturators. J Prosthet Dent 1991;66:136-8.

30. Elliott DJ. The hollow bulb obturator: its fabrication using one denture flask. Quintessence Dent Technol 1983;7:13-4

31. DaBreo EL. A light-cured interim obturator prosthesis. A clinical report. J Prosthet Dent 1990;63:371-3. 